\title{
The Attitude of Women Planning Pregnancy and/or Having Children Towards Vaccinations: A Cross- Sectional Survey Study
}

\section{Carlo Bieńkowski ( $\sim$ carlo.bienkowski@gmail.com )}

Medical University of Warsaw: Warszawski Uniwersytet Medyczny https://orcid.org/0000-0002-64884576

\section{Monika Kowalczyk}

Medical University of Warsaw: Warszawski Uniwersytet Medyczny

\section{Agata Golik}

Medical University of Warsaw: Warszawski Uniwersytet Medyczny

\section{Joanna Kacperczyk-Bartnik}

Medical University of Warsaw: Warszawski Uniwersytet Medyczny

\section{Paweł Bartnik}

Medical University of Warsaw: Warszawski Uniwersytet Medyczny

\section{Agnieszka Dobrowolska-Redo}

Medical University of Warsaw: Warszawski Uniwersytet Medyczny

\section{Ewa Romejko-Wolniewicz}

Medical University of Warsaw: Warszawski Uniwersytet Medyczny

Maria Pokorska-Śpiewak

Medical University of Warsaw: Warszawski Uniwersytet Medyczny

\section{Research}

Keywords: anti-vaccination movement, infections, newborn diseases, pregnancy, vaccines

Posted Date: December 29th, 2021

DOI: https://doi.org/10.21203/rs.3.rs-1150867/v1

License: (c) (i) This work is licensed under a Creative Commons Attribution 4.0 International License. Read Full License 


\section{Abstract \\ Background}

Infectious disease agents can cause serious fetopathy. Implementing appropriate prevention methods while planning pregnancy can help avoid some of them.

\section{Methods}

A cross-sectional survey study was performed. The questionnaire investigated attitudes towards vaccinations, as well as opinions on anti-vaccine movements and the so-called "chickenpox parties".

\section{Results}

The study group consisted of 2402 women, age range was 16-54 years (median: 31 years). Most women were from cities $>100,000$ inhabitants $(49.7 \%, 1194 / 2402)$ and had higher education $(71.9 \%$, $1726 / 2402)$. A positive attitude towards vaccinations was more common among younger, nulliparous women from big cities ( $p=0.02, p=0.04$ and $p=0.01$, respectively). 2068/2402 (86.1\%) of them were not vaccinated before pregnancy and 1931/2402 (80.4\%) of women were not vaccinated during pregnancy. While most women (1545/2402, 64.3\%) considered vaccination safe, and effective (1904/2402, 79.3\%) against infectious diseases, many $(n=296 / 240212.3 \%)$ have no opinion on the so-called chickenpox party.

\section{Conclusions}

Most women in Poland have a positive attitude towards vaccinations and consider vaccines a safe and effective method of protection against infectious diseases. Since a significant proportion of women were not vaccinated before or during pregnancy and about $12 \%$ of women are undecided, the physician's role is crucial in educating and persuading the patient to be vaccinated

\section{Background}

Intrauterine or perinatally-transmitted infections are a significant cause of fetal and neonatal mortality and an important contributor to morbidity in early and late childhood. The term TORCH complex is used to describe common mother-to-child infections, including: toxoplasmosis, other: syphilis, hepatitis B and $\mathrm{C}$ viruses (HBV and HCV), human immunodeficiency virus (HIV), human papillomavirus (HPV), parvovirus B19, varicella and zoster virus (VZV) and enteroviruses. The acronym also includes rubella, cytomegalovirus (CMV) and herpes simplex virus (HSV). The majority in this group are infections of viral etiology (1). 
Preconception care should be given to every woman of childbearing age. The main goals of antenatal care include identifying potential risks to the mother, fetus and pregnancy, and providing information about potential risk factors and intervention options $(2,3)$ (Table 1$)$.

A detailed medical interview is essential for risk assessment. It is important to gather accurate information about past and present chronic diseases, including diabetes and hypertension, as well as family history of genetic and congenital malformations. Information about gynaecological diseases and previous obstetric history, data on the course of previous pregnancies, way of their termination, and data on children's health are also important $(2,4)$. Regular medical visits and laboratory testing reduce the risk of complications during pregnancy and delivery $(2,4)$.

On January 1, 2019, new recommendations were introduced in Poland, outlining the scope of diagnostic tests and medical consultations that should be performed throughout the course of pregnancy. The current calendar of pregnancy examinations is presented in Table 1. Many interventions before and during pregnancy can reduce the incidence of birth defects, congenital diseases, fetal impairment or pregnancy complications. Some interventions need to be performed before conception. They include glycemic control, weight loss, folic acid supplementation (5-7). Pregnant women should give up drinking and smoking. It is also important to discontinue teratogenic drugs, and if the patient needs treatment, these drugs should be replaced with medications that are safe for the fetus. It is also important to maintain healthy body weight, as obesity increases the risk of birth defects and may cause many complications for the mother $(5,6)$. During pregnancy, women should pay attention to hygiene. Handwashing, avoiding eating uncooked meat and unpasteurised food reduce the risk of developing diseases such as toxoplasmosis, and listeriosis $(5,7)$.

According to the recommendations of the Advisory Committee on Immunization Practices at Centers for Disease Control and Prevention and the American College of Obstetrics and Gynecology, a woman who is planning to become pregnant should be vaccinated against rubella (MMR) and chickenpox at least 4 weeks before conception (as these vaccinations are contraindicated during pregnancy), unless she has had varicella or rubella or has been vaccinated against these diseases. From the second or trimester of pregnancy, every woman should be vaccinated against influenza and hepatitis B (unless she has previous history of these diseases or has been vaccinated against them). Vaccination against pertussis (DTP) with an acellular vaccine between 27 and 34 weeks (36 weeks in Poland) of pregnancy in order is also recommended to pass the antibodies to her child (irrespective of her previous history of infection or immunization) (8).

\section{Objectives}

The aim of the study was to evaluate the attitude of Polish women who have children or are planning a pregnancy towards vaccination, infectious diseases that may cause vertical infections, their medical knowledge and the main sources of medical information. 


\section{Material And Methods}

A cross-sectional survey study was performed anonymously, which checked the attitudes of Polish women planning pregnancy, being pregnant or already having children towards various aspects related to vaccinations and vertical infections. Moreover, attitudes towards anti-vaccine movements and chickenpox parties were also analyzed. The questionnaire was developed for the purpose of this study and the survey was conducted using the google form, which was posted on social media groups for women planning pregnancy, being pregnant or for mothers' groups from Poland. Groups were chosen on the basis of the names "Mothers", "Future mothers", "Planning pregnancy" and a combination of these titles along with the names of specific areas of Poland, namely provinces and voivodeships. Every surveyed woman, when completing the questionnaire, had to agree to complete it and had given permission to analyze and publish data collected from her survey. Medical University of Warsaw's Ethics Committee does not issue an opinion on the conduct of survey, retrospective and non-invasive studies. Therefore ethics approval was waived.

Normality of continuous variables was tested using Shapiro-Wilk's test. The U-Mann Whitney test was used to compare continuous variables and the $\mathrm{chi}^{2}$ test was used to evaluate categorical variables. A p value of $<0.05$ was considered significant. Logistic regression was used to calculate adjusted odds ratios and to determine variables independently associated with the attitude towards vaccinations. Statistical analysis was performed using programme Statistica version 13.3.

\section{Results}

The collected data were grouped into 4 subgroups:

- study group characteristics,

- vaccination-related data,

- infectious diseases during pregnancy,

- attitude towards anti-vaccine movements and chickenpox parties.

\section{Study group characteristics}

The study group consisted of 2402 women planning pregnancy or having children. The age range was 16-54 years (median: 31 years). The most numerous group consisted of women living in cities $>100,000$ inhabitants ( $n=1194 / 2402,49.7 \%)$, with higher education ( $n=1726 / 2402,71.9 \%)$, married $(n=1841 / 2402$, $76.6 \%)$ and in a stable relationship ( $n=2329 / 2402,97 \%)$. Most of the surveyed women had been once pregnant $(n=1009 / 2402,42 \%)$ and gave birth once $(n=1211 / 2402,50.4 \%)$. When implementing the survey, 788/2402 (32.8\%) of women were pregnant. The survey also checked if women have contact with school-age children $(1491 / 2402,62.1 \%)$ and the source of their knowledge about vaccines, which was mostly medical staff $(1848 / 2402,76.9 \%)$. Baseline characteristics of the study group are presented in Table 2. 


\section{Vaccination-related data}

The survey analyzed the vaccination coverage among Polish women. The analysis included whether the women were vaccinated appropriately when planning pregnancy, and whether these vaccinations were recommended by doctors. It was verified, whether women were vaccinated during pregnancy against the diseases according to recommendations. The study also checked women's willingness to vaccinate their children, and if they consider vaccination to be safe and effective against infectious diseases.

Most women had been previously vaccinated according to their vaccination schedule [against tuberculosis, hepatitis B, DTP, MMR, polio ( $n=1283 / 2402,53.4 \%$ for polio to $1728 / 2402,71.9 \%$ for DTP) almost a quarter of women did not remember what infectious diseases they were vaccinated against in the past ( $n=566 / 2402,23.6 \%$ ) (Figure $1 A)$. The vast majority of women had not been vaccinated while planning pregnancy $(n=2069 / 2402,86.1 \%)$ (Figure 1B). This may be due to the fact that physicians often do not recommend vaccinations before the pregnancy $(n=1989 / 2402,82.2 \%)$. The study shows that only about 3\% (67-91/2402, 2.8-3.8\%) of physicians recommended vaccination against influenza or pertussis to pregnant women. Nonetheless $1712 / 2402(71.27 \%)$ of women have a positive attitude towards vaccinations. It was more common among nulliparous, younger women living in more populous cities (Table 3). Seventy one point three percent $(n=1712 / 2402)$ of women consider vaccinations necessary for their children's health. Sixty four point three percent $(n=1544 / 2402)$ of respondents consider vaccinations safe for their children, while Seventy nine point three percent ( $n=1905 / 2402)$ consider them effective in preventing infectious diseases.

\section{Infectious diseases during pregnancy}

The study also checked women's knowledge of the risk associated with infectious diseases during pregnancy. Polish women were also asked about the most dangerous, in their opinion, pathogenic factors that may affect the development of the fetus (Table 4). Seventy three percent $(n=1752 / 2402)$ of women have never heard the acronym TORCH. The vast majority of women know that fetal birth defects can be caused by infectious agents $(n=1718 / 2402,74.1 \%)$, but almost a quarter were not aware of this fact $(n=544 / 2402,22.6 \%)$. Among the 5 most dangerous in surveyed women's opinion infectious diseases for the fetus, were: toxoplasmosis ( $n=1594 / 2402,66.4 \%)$, rubella ( $n=1195 / 2402,49.8 \%)$, CMV $(n=912 / 2402$, $38 \%), \operatorname{HIV}(n=810 / 2402,33.7 \%)$ and measles $(n=643 / 2402,26.8 \%)$. According to respondents, the 5 most dangerous fetal defects caused by infectious agents were: nervous system defects $(n=1599 / 2402$, $66.6 \%)$, heart defects $(n=1549 / 2402,64.5 \%)$, intrauterine death $(n=1445 / 2402,60.2 \%)$, extremities hypoplasia $(n=1009 / 2402,42 \%)$, and body mass deficiency $(n=729 / 2402,30.3 \%)$.

\section{Attitude towards anti-vaccine movements and chickenpox parties}

Fifty seven percent ( $n=1350 / 2402)$ of the surveyed women fully disagree with anti-vaccine movements, $22.9 \%(n=549 / 2402)$ partially agree, and $11.8 \%(n=284 / 2402)$ have no opinion and $6.2 \%(n=149 / 2402)$ fully agree. In case of chickenpox party, as much as $83.1 \%(n=2013 / 2402)$ of women consider this phenomenon dangerous for children's health, 12.3\% ( $n=296 / 2402)$ have no opinion on this matter, and 
3.9\% ( $n=93 / 2402)$ consider it a good way for children to acquire immunity. Women living in cities > 100,000 inhabitants considered chickenpox party more often as a dangerous phenomenon for children's health $(51.19 \%, n=989$ vs. $43.62 \%, n=205, p=0.04)$.

\section{Discussion}

Our study revealed that a positive attitude towards vaccinations was more common among nulliparous, younger women living in more populous cities (Table 4).

Interestingly, it seems that there is no real correlation between attitudes towards vaccination and socioeconomic status or level of education. Much better predictors are high levels of underground thinking, low tolerance to perceived personal freedom, aversion to needles or blood, and religious issues. But most importantly, worried parents are the consumers of misinformation (9).

A German study conducted by Betsch $\mathrm{C}$ et al. demonstrated that accessing vaccine-critical websites for five to ten minutes increases the perception of risk of vaccination and decreases the perception of risk resulting from omitting vaccinations as well as the willingness to vaccinate (10). This is worrying given that as many as $76.1 \%(n=1829 / 2402)$ of surveyed women use the internet as a source of knowledge about vaccination.

Anti-vaccine movement is a colloquial term for initiatives of people who negate the effectiveness and expediency of vaccinating. The history of anti-vaccination movements dates back to the nineteenth century, when Edward Jenner proved that vaccinia virus infection protects against smallpox virus infection and its complications. Already then many people disapproved his actions (11). Nowadays, the anti-vaccine movement has increased significantly, following the publication of a paper by Andrew Wakefield in 1998 in which he argued that measles, mumps, rubella (MMR) vaccination was associated with autism (12). The greatest intensification of anti-vaccine movements in Europe took place after the publication of Wakefield's pseudo-research, the consequences of which we have to face today. In the UK, the MMR vaccination rate dropped from $92 \%$ in 1996 to $84 \%$ in 2002. In 2003, the rate was as low as $61 \%$ in some parts of London, far below the rate needed to avoid an epidemic of measles (13). Anti-vaccine movements are also gaining more and more popularity in Poland. In our country, the number of people who avoid vaccination is constantly increasing. In 2010, as a result of the parents' refusal, 3437 children were not vaccinated with compulsory vaccines, whereas in 2018 about 40,000 parents had already evaded their vaccinations (14). In a survey conducted by Furman et al. $2.3 \%$ of parents declared that they have avoided mandatory childhood vaccination at least once, $8.5 \%$ of parents would stop vaccinating their children if the vaccination obligation was abolished (14). The aftermath of these activities can also be seen in Poland, the level of vaccination against measles, mumps and rubella fell below $95 \%$, ensuring a safe level for society. Our study showed that $57 \%(n=1350 / 2402)$ of the surveyed women fully disagree with anti-vaccine movements. It is difficult to reduce this tendency if women planning pregnancy in Poland are not vaccinated according to recommendations $(86.1 \%, n=2069 / 2402)$. On the other hand, if a woman is planning her pregnancy and is under medical care, the physician should inform her about the 
recommended vaccinations. Analyzing the vaccination coverage of Polish women against influenza, data from the National Institute of Public Health - National Institute of Hygiene show that in 2018 only $2.5 \%$ of people have been vaccinated against influenza (14). Our study showed that only $3 \%$ of doctors recommended pregnant women to vaccinate against influenza.

Recently popular among parents are the so-called "chickenpox party", these are deliberate organized meetings of healthy children with people infected with chickenpox virus. The purpose of the meeting is to infect healthy children so that their immune system develops natural immunity after illness (15). An Italian Study revealed that $2.2 \%$ of the parents believed that varicella could cause serious health problems (16). In our study $83.1 \%(n=2013 / 2402)$ of women consider the phenomenon of chickenpox party as dangerous for their children's health. This attitude was more common in women living in cities > 100,000 inhabitants $(51.19 \%, n=989$ vs. $43.62 \%, n=205, p=0.04)$.

\section{LIMITATIONS OF THE STUDY}

Since it was a questionnaire study, women completing the survey might have not understood some questions, since it was performed via social media, we could not explain it enough for some of them. On the other hand, most of surveyed women had higher education, which may suggest that they understood the questionnaire properly. However, one cannot be sure if the answers were honest. We decided to collect a high amount of correctly completed surveys in order to minimize the risk of getting dishonest answers and having unreliable results.

Most of the surveyed women live in big cities. It might be worth considering extending the study among rural areas in order to collect more representative data, especially when most women are obtaining their knowledge about vaccines mainly from medical staff, and medical care is more limited in the countryside.

\section{Conclusions}

To sum up, most women in Poland want to be vaccinated and to vaccinate their children, they consider vaccines safe and effective against infectious diseases. A significant proportion of women planning to become pregnant or being pregnant is not vaccinated, the role of physician convincing the patient to be vaccinated is crucial in this matter. About $12 \%$ of women are the undecided fraction, and the educational role of physicians is essential to convince them of the importance of vaccination.

\section{Abbreviations}

HBV - hepatitis B virus

HCV - hepatitis C virus

HIV - human immunodeficiency virus 
HPV - human papillomavirus

VZV - varicella-zoster virus

$\mathrm{CMV}$ - cytomegalovirus

HSV - herpes simplex virus

MMR - measles, mumps, rubella

DTP - diphtheria, tetanus, pertussis

TORCH - toxoplasmosis, other, rubella, cytomegalovirus, herpes simples virus

VDRL - venereal disease research laboratory (testing towards syphilis)

IgG - immunoglobulin $\mathrm{G}$

$\lg M$ - immunoglobulin $M$

Hbs - hepatitis B virus antigen

\section{Declarations}

\section{Conflict of interest:}

The authors declare no conflict of interest.

\section{Ethics approval and consent to participate}

The design of the work conforms to standards currently applied in Medical University of Warsaw's Bioethics Committee. Approval number: AKBE/131/2021.

\section{Ethics and consent to participate}

Written informed consent to participate was obtained from all participants.

\section{Consent for publication}

Not applicable.

\section{Availability of data and material}

The data sets used and/or analyzed during the current study can be made available by the corresponding author on reasonable request.

Funding 
No funding was received.

\section{Authors' contributions}

$\mathrm{CB}, \mathrm{MK}, \mathrm{AG}, \mathrm{JKB}$ conceived and designed the analysis, collected the data, wrote the paper, PB conceived and designed the analysis, performed the analysis. ADR, ERW and MPŚ onceived and designed the analysis, contributed to critically refining the article, . All authors have read and approved the final article.

\section{Acknowledgements}

Not Applicable

\section{References}

1. Neu N, Duchon J, Zachariah P. TORCH infections. Clin Perinatol. 2015;42(1):77-103, viii.

2. Johnson K, Posner SF, Biermann J, Cordero JF, Atrash HK, Parker CS, et al. Recommendations to improve preconception health and health care-United States. A report of the CDC/ATSDR Preconception Care Work Group and the Select Panel on Preconception Care. MMWR Recomm Rep. 2006;55(Rr-6):1-23.

3. Mazza D, Chapman A, Michie S. Barriers to the implementation of preconception care guidelines as perceived by general practitioners: a qualitative study. BMC Health Serv Res. 2013;13:36.

4. Bernstein PS, Sanghvi T, Merkatz IR. Improving preconception care. J Reprod Med. 2000;45(7):54652.

5. Viswanathan M, Treiman KA, Kish-Doto J, Middleton JC, Coker-Schwimmer EJ, Nicholson WK. Folic Acid Supplementation for the Prevention of Neural Tube Defects: An Updated Evidence Report and Systematic Review for the US Preventive Services Task Force. Jama. 2017;317(2):190-203.

6. Korenbrot CC, Steinberg A, Bender C, Newberry S. Preconception care: a systematic review. Matern Child Health J. 2002;6(2):75-88.

7. 2. Classification and Diagnosis of Diabetes: Standards of Medical Care in Diabetes-2021. Diabetes Care. 2021;44(Suppl 1):S15-s33.

8. Swamy GK, Heine RP. Vaccinations for pregnant women. Obstet Gynecol. 2015;125(1):212-26.

9. Swingle CA. How Do We Approach Anti-Vaccination Attitudes? Mo Med. 2018;115(3):180-1.

10. Betsch $C$, Renkewitz F, Betsch T, Ulshöfer $C$. The influence of vaccine-critical websites on perceiving vaccination risks. J Health Psychol. 2010;15(3):446-55.

11. Dubé $E$, Vivion M, MacDonald NE. Vaccine hesitancy, vaccine refusal and the anti-vaccine movement: influence, impact and implications. Expert Rev Vaccines. 2015;14(1):99-117.

12. Jolley D, Douglas KM. The effects of anti-vaccine conspiracy theories on vaccination intentions. PLoS One. 2014;9(2):e89177.

13. Murch S. Separating inflammation from speculation in autism. Lancet. 2003;362(9394):1498-9. 
14. Czarkowski PM et al. Vaccinations in Poland in 2018 [National Institute of Public Health - National Institute of Hygiene Department of Epidemiology and Surveillance of Infectious Diseases web site] January 2019. Available at: http://wwwold.pzh.gov.pl/oldpage/epimeld/2018/Sz_2018.pdf. Accessed February 2021

15. Furman FM, Zgliczyński WS, Jankowski M, Baran T, Szumowski Ł, Pinkas J. The State of Vaccine Confidence in Poland: A 2019 Nationwide Cross-Sectional Survey. Int J Environ Res Public Health. 2020;17(12).

16. Hambleton S, Arvin AM. Chickenpox party or varicella vaccine? Adv Exp Med Biol. 2005;568:11-24.

17. Vezzosi L, Santagati G, Angelillo IF. Knowledge, attitudes, and behaviors of parents towards varicella and its vaccination. BMC Infectious Diseases. 2017;17(1):172.

\section{Tables}

Table 1 Recommendations of diagnostic tests towards infectious diseases during pregnancy according to Polish Journal of Laws.

\begin{tabular}{|c|c|}
\hline Examination date & Diagnostic tests \\
\hline \multirow{4}{*}{$\begin{array}{l}\text { Up to the } 10 \text { th week of } \\
\text { gestation or at the time of } \\
\text { first reporting }\end{array}$} & 1. VDRL test.* \\
\hline & 2. HIV and HCV testing. \\
\hline & $\begin{array}{l}\left.\text { 3. Testing for toxoplasmosis ( } \lg G^{\star *}, \lg M^{\star \star *}\right) \text {, unless the pregnant } \\
\text { woman shows a result confirming the presence of } \operatorname{lgG} \text { antibodies from } \\
\text { before pregnancy. }\end{array}$ \\
\hline & $\begin{array}{l}\text { 4. Rubella test (lgG, IgM), if the pregnant woman has not been ill or } \\
\text { has not been vaccinated or in the absence of information. }\end{array}$ \\
\hline $\begin{array}{l}\text { Week } 21-26 \text { th of } \\
\text { gestation }\end{array}$ & $\begin{array}{l}\text { 1. In women with negative results in the first trimester - testing for } \\
\text { toxoplasmosis }(\lg M) \text {. }\end{array}$ \\
\hline \multirow{4}{*}{$\begin{array}{l}\text { Week 33-37th of } \\
\text { gestation }\end{array}$} & 1. Testing the $\mathrm{HBs}^{\star \star \star \star}$ antigen presence. \\
\hline & 2. HIV testing. \\
\hline & $\begin{array}{l}\text { 3. Vaginal and rectal culture for B-hemolytic streptococci (35-37 } \\
\text { weeks of gestation). }\end{array}$ \\
\hline & $\begin{array}{l}\text { 4. VDRL and HCV studies in a group of women with an increased risk } \\
\text { of infection. }\end{array}$ \\
\hline
\end{tabular}

*VDRL - venereal disease research laboratory (testing towards syphilis)

**IgG - immunoglobulin G

$\star \star \star \lg M-$ immunoglobulin $\mathrm{M}$

$\star * \star * H b s$ - hepatitis B virus antigen 
Table 2: Baseline characteristics of the study group. 
$\mathrm{n}=2402 \quad \%$

Place of residence

\begin{tabular}{|c|c|c|c|}
\hline & village & 549 & 22.8 \\
\hline & city: <10 000 & 167 & 7 \\
\hline & city: 10000 - 100000 & 492 & 20.5 \\
\hline & city: > 100000 & 1194 & 49.7 \\
\hline \multicolumn{4}{|l|}{ Education } \\
\hline & medium & 530 & 22.01 \\
\hline & vocational school & 97 & 4 \\
\hline & higher & 1726 & 71.9 \\
\hline & other & 492 & 2 \\
\hline \multicolumn{4}{|l|}{ Marital status } \\
\hline & single & 440 & 18.03 \\
\hline & married & 1841 & 76.6 \\
\hline & divorced & 69 & 2.09 \\
\hline & widowed & 52 & 2.02 \\
\hline \multicolumn{4}{|l|}{ Stable relationship } \\
\hline & yes & 2329 & 97 \\
\hline & no & 73 & 3 \\
\hline \multicolumn{4}{|l|}{ Number of pregnancies } \\
\hline & 0 pregnancies & 98 & 4.1 \\
\hline & 1 pregnancy & 1009 & 42 \\
\hline & 2 pregnancies & 832 & 34.6 \\
\hline & 3 pregnancies & 299 & 12.4 \\
\hline & $>4$ pregnancies & 164 & 6.9 \\
\hline \multicolumn{4}{|l|}{ Number of births } \\
\hline & 0 births & 243 & 10.1 \\
\hline & 1 birth & 1211 & 50.4 \\
\hline & 2 births & 754 & 31 \\
\hline
\end{tabular}




\begin{tabular}{|lll|}
\hline not pregnant & 456 & 19 \\
\hline pregnant & 1614 & 67.2 \\
\hline $\begin{array}{l}\text { Not pregnant, planning } \\
\text { pregnancy }\end{array}$ & 332 & 13.8 \\
\hline
\end{tabular}

\section{Sources of information about medical knowledge}

\begin{tabular}{lll} 
medical staff & 1848 & 76.9 \\
\hline books & 837 & 34.7 \\
\hline press & 426 & 17.7 \\
\hline internet & 1829 & 76.1 \\
\hline television & 298 & 12.4 \\
\hline family & 748 & 31.3 \\
\hline friends & 756 & 31.5 \\
\hline lamaze class & 318 & 13.2 \\
\hline university class & 5 & 0.2 \\
\hline science publications & 3 & 0.1 \\
\hline leaflets & 85 & 3.5 \\
\hline
\end{tabular}

Table 3 Factors influencing the attitude towards vaccinations.

\begin{tabular}{|llll|}
\hline attitude towards vaccinations & positive & negative & p-value \\
& 1712 & 690 & \\
\hline median age & $30.76+-5.5$ years & $31.34+-5.2$ years & 0.002 \\
\hline parous & $70.63 \%$ & $29.37 \%$ & 0.0039 \\
\hline nulliparous & $76.95 \%$ & $23.05 \%$ & \\
\cline { 1 - 2 } city $>100000$ & $51.34 \%$ & $45.65 \%$ & 0.013 \\
city $<100000$ & $48.66 \%$ & $54.35 \%$ & \\
\hline
\end{tabular}


Table 4 presents which infectious diseases are Polish women the most afraid or would have been afraid of due to their pregnancy/planning pregnancy.

A. Infectious diseases that Polish women are the most afraid of due to their pregnancy.

\begin{tabular}{|lll|}
\hline Infectious disease & & \\
& & \\
& $\mathbf{n}=2402$ & $\%$ \\
\hline toxoplasmosis & 1594 & 66.4 \\
\hline rubella & 1195 & 49.8 \\
\hline CMV & 912 & 38 \\
\hline HIV & 810 & 33.7 \\
\hline measles & 643 & 26.8 \\
\hline Chickenpox & 603 & 25.1 \\
\hline herpes & 575 & 23.9 \\
\hline syphilis & 515 & 21.4 \\
\hline pertussis & 484 & 20.1 \\
\hline hepatitis B & 483 & 20.1 \\
\hline tuberculosis & 450 & 18.7 \\
\hline mumps & 395 & 16.4 \\
\hline influenza & 392 & 16.3 \\
\hline tetanus & 271 & 11.3 \\
\hline polio & 247 & 10.3 \\
\hline diphtheria & 157 & 6.5 \\
\hline I am not afraid & 126 & 5.25 \\
\hline
\end{tabular}

B. Congenital defects caused by infections agents according to Polish women. 


\begin{tabular}{|lll|}
\hline Congenital defect associated with infectious agent & $\mathrm{n}=2402$ & $\%$ \\
\hline defects of the nervous system & 1599 & 66.6 \\
\hline congenital heart defects & 1549 & 64.5 \\
\hline intrauterine death & 1445 & 60.2 \\
\hline hydrocephalus & 1009 & 42 \\
\hline hypoplasia of the limbs & 1009 & 42 \\
\hline weight loss & 729 & 30.3 \\
\hline deafness & 694 & 28.9 \\
\hline does not know & 558 & 23.2 \\
\hline AIDS & 471 & 19.6 \\
\hline congenital cataract & 237 & 9.9 \\
\hline there is no risk & 41 & 1.71 \\
\hline
\end{tabular}

Figures 
A

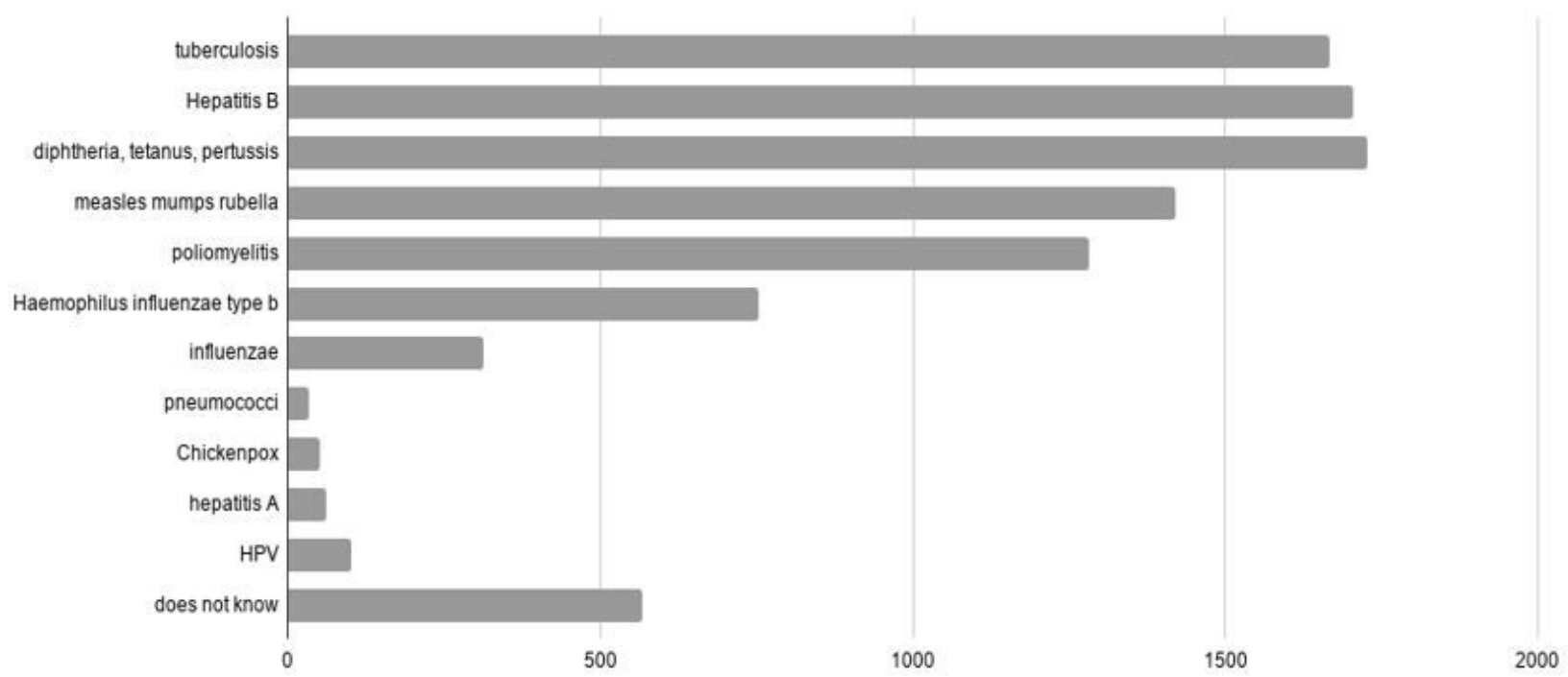

$\mathrm{B}$

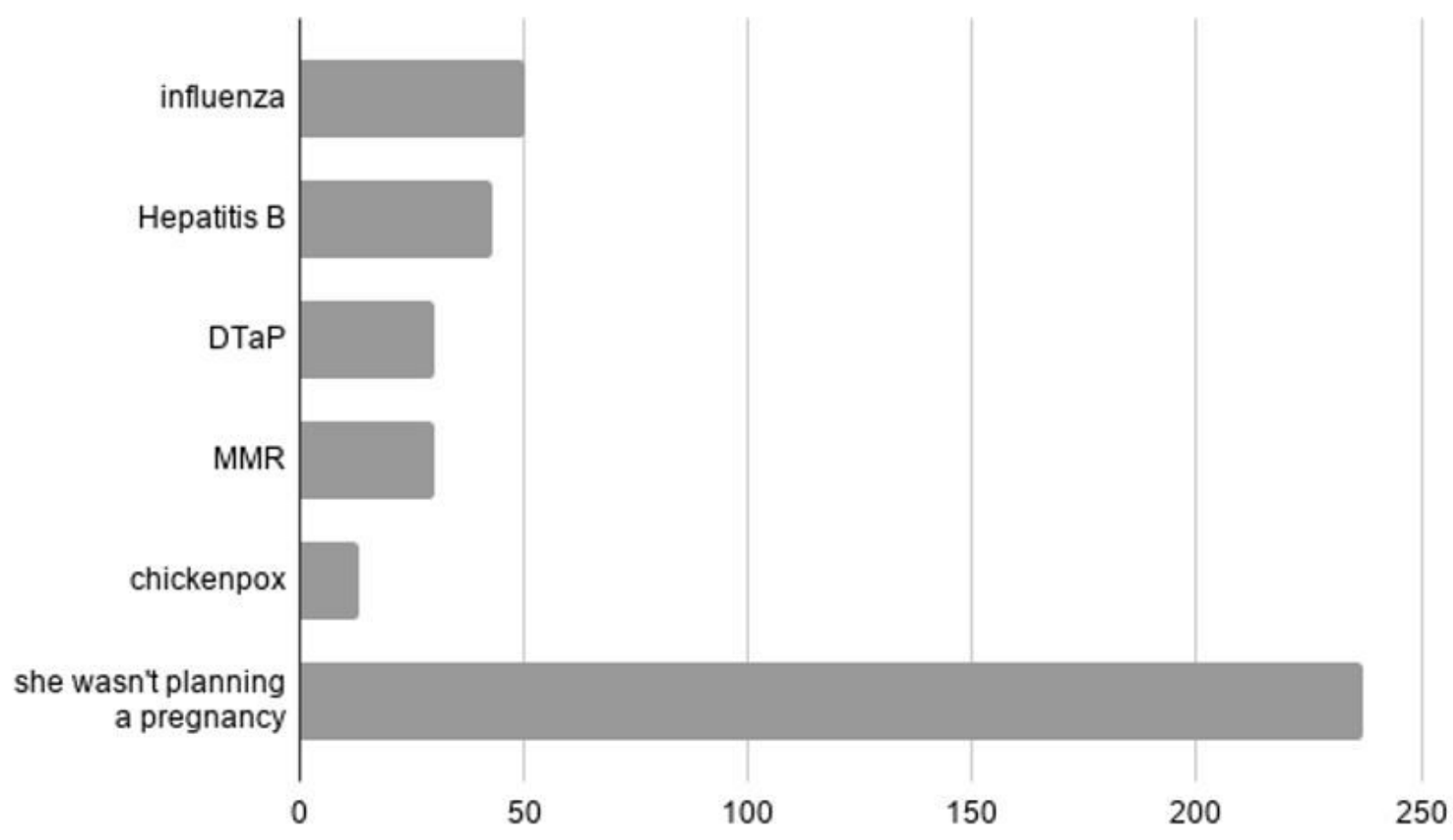

Figure 1

Vaccinations in Polish women planning pregnancy.

A. Data presents which pathogens the surveyed women had been vaccinated against according to their individual vaccination schedule. 
B. Data presents which pathogens the surveyed women had been vaccinated against due to planning her pregnancy. 